
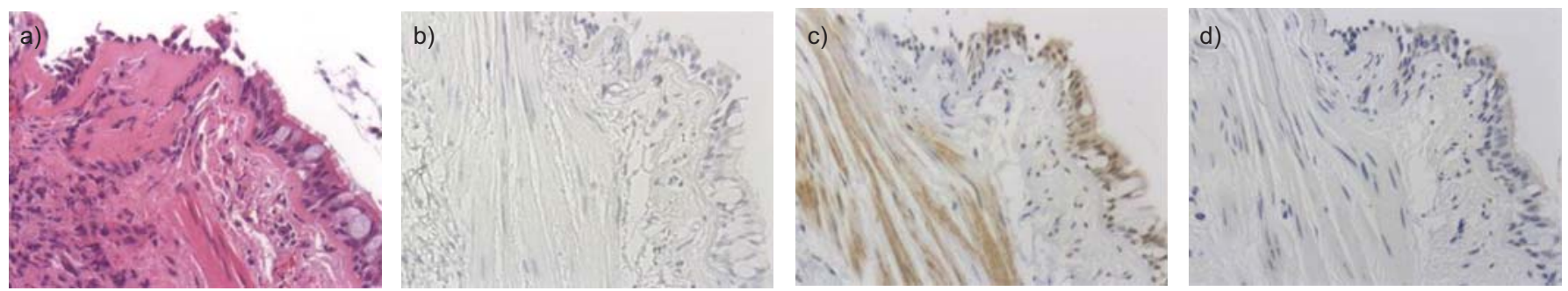

FIGURE 2. Immunostaining of airway biopsy tissue with mouse anti-interleukin (IL)-18 monoclonal antibodies and anti-IL-18R $\alpha$ in an allergic asthma subject (200 $\times$ ) Positive staining for IL-18 is seen in the airway epithelium and airway smooth muscle, while positive staining for IL-18 receptor (IL-18R) $\alpha$ is seen only in the airway epithelium. a) Haematoxylin and eosin; b) negative control; c) IL-18; d) IL-18R $\alpha$.

through its role in the development of IgE and AHR. Further studies to elucidate the importance of IL-18 in allergic asthma would require the availability of humanised anti-IL-18 monoclonal antibodies to block the effects of IL-18.

\section{H. Imaoka*,\#, G.M. Gauvreau*, R.M. Watson*, S.G. Smith*, B. Dua*, A.J. Baatjes*, K. Howie*, T. Hoshino", K.J. Killian*, H. Aizawa ${ }^{\#, \dagger}$ and P.M. O'Byrne*}

*Dept of Medicine, Michael G. DeGroot School of Medicine, Faculty of Health Sciences, McMaster University, Hamilton, ON, Canada, and "Division of Respirology, Neurology and Rheumatology, Dept of Medicine, Kurume University School of Medicine, Kurume, Japan.

Correspondence: P.M. O'Byrne, HSC 3W10, McMaster University, 1200 Main St West, Hamilton, ON, L8N 3Z5, Canada. E-mail: obyrnep@mcmaster.ca

Support Statement: This study was supported by the Canadian Institutes for Health (research grant \#9362).

Statement of Interest: A statement of interest for P.M. O'Byrne can be found at www.erj.ersjournals.com/site/misc/statements. xhtml

Acknowledgements: We thank T. Kawayama, Y. Sakazaki and C. Ohki (all Kurume University, Kurume, Japan) for their technical assistance.

\section{REFERENCES}

1 Cohn L, Elias JA, Chupp GL. Asthma: mechanisms of disease persistence and progression. Annu Rev Immunol 2004; 22: 789-815.

2 Okamura H, Tsutsi $\mathrm{H}$, Komatsu T, et al. Cloning of a new cytokine that induces IFN- $\gamma$ production by T cells. Nature 1995; 378: 88-91.

3 Hoshino T, Yagita H, Ortaldo JR, et al. In vivo administration of IL18 can induce IgE production through Th2 cytokine induction and up-regulation of CD40 ligand (CD154) expression on CD4+ T cells. Eur J Immunol 2000; 30: 1998-2006.

4 Harada M, Obara K, Hirota T, et al. A functional polymorphism in IL-18 is associated with severity of bronchial asthma. Am J Respir Crit Care Med 2009; 180: 1048-1055.

$5 \mathrm{Wu} \mathrm{H}$, Romieu I, Shi M, et al. Evaluation of candidate genes in a genome-wide association study of childhood asthma in Mexicans. J Allergy Clin Immunol 2010; 125: 321-327.

6 Zhu G, Whyte MK, Vestbo J, et al. Interleukin 18 receptor 1 gene polymorphisms are associated with asthma. Eur J Hum Genet 2008; 16: 1083-1090.

7 Juniper EF, Frith PA, Dunnett C, et al. Reproducibility and comparison of responses to inhaled histamine and methacholine. Thorax 1978; 33: 705-710.

8 Imaoka H, Hoshino T, Takei S, et al. Interleukin-18 production and pulmonary function in COPD. Eur Respir J 2008; 31: 287-297.

9 Wong CK, Ho CY, Ko FW, et al. Proinflammatory cytokines (IL-17, IL-6, IL-18 and IL-12) and Th cytokines (IFN- $\gamma$, IL-4, IL-10 and IL-13) in patients with allergic asthma. Clin Exp Immunol 2001; 125: 177-183.

10 Tanaka H, Miyazaki N, Oashi K, et al. IL-18 might reflect disease activity in mild and moderate asthma exacerbation. J Allergy Clin Immunol 2001; 107: 331-336.

DOI: 10.1183/09031936.00033811

\title{
Pulmonary malakoplakia: a rare presentation mimicking extensive stage IV lung cancer
}

\section{To the Editors:}

Herein, we report a 74-yr-old female who presented with several weeks history of persistent cough productive of mucoid phlegm with specks of haemoptysis. This was associated with fatigue and poor appetite. She also reported a minor episode of nosebleed. She denied any shortness of breath, chest pain, weight loss or any alteration of bowel habit. She complained of some intermittent left-sided pleuritic-type chest pain, which prompted a chest radiograph and urgent referral to the chest clinic thereafter.

Her past medical history included left breast surgery 11 yrs ago for ductal carcinoma in situ, atrial fibrillation, essential 

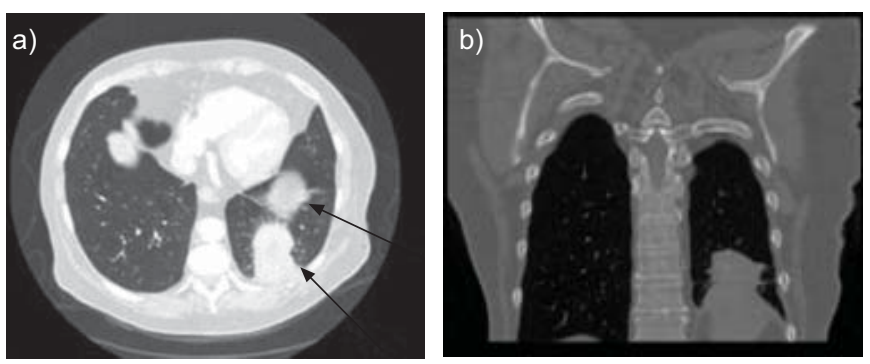

FIGURE 1. a) Soft tissue mass (arrows) at the lower lobe of the left lung extending through the left hemidiaphragm to the upper pole of the left kidney. b) Coronal view of mass in (a).

hypertension, sciatica and psoriasis. She was an ex-smoker with a 37-pack-yr history.

Initial blood tests showed a haemoglobin level of $107 \mathrm{~g} \cdot \mathrm{L}^{-1}$, a white cell count of $18.6 \times 10^{9}$ cells $\cdot \mathrm{L}^{-1}$ (lymphocyte count $1.89 \times 10^{9} \mathrm{cells} \cdot \mathrm{L}^{-1}$ ) and a platelet count of $128 \times 10^{9} \mathrm{cells} \cdot \mathrm{L}^{-1}$. Liver function tests were normal and she was HIV negative.

A chest radiograph revealed the presence of a posteriorly located left lower lobe mass. A computed tomography (CT) scan (fig. 1) confirmed the presence of a pleural-based mass posteriorly in the left lower lobe measuring $3.7 \times 3.2 \mathrm{~cm}$ with spiculated margin in contiguity with the dome of the left hemidiaphragm and extending into the abdomen. The mass appeared to be infiltrating the spleen and the upper pole of the left kidney. The rest of the scan was unremarkable. A positron emission tomography (PET) scan confirmed the presence of an fluorodeoxyglucose-avid lesion in the left lower lobe of the lung extending to the left upper quadrant, adjacent to the upper pole of the left kidney and spleen. A CT-guided biopsy of the lesion was obtained from the mass in the region just above the left kidney.

The biopsy revealed small fragments of tissue predominantly comprising relatively large polygonal-appearing cells with abundant, slightly granular cytoplasm and monomorphic nuclei, which were not typical of bronchogenic carcinoma in appearance. Given the site biopsied, the possibility that the large polygonal cells present were of adrenal cortical origin was considered but the immunohistochemical profile (PanCK, CAM 5.2, CK7, CD10, thyroid transcription factor-1, synaptophisin,
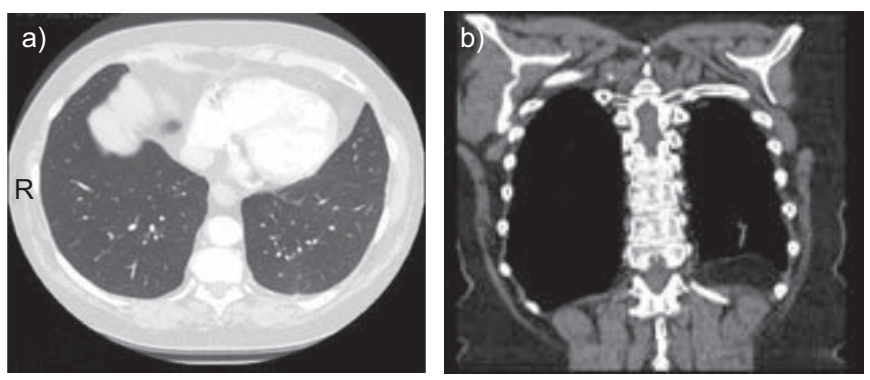

FIGURE 3. Follow-up contrast-enhanced computed tomography images showing a considerable decrease in the size of the lesion.

melan A, inhibin, calretinin negative) was not consistent with this. Within some of the large polygonal cells, spherical bodies were identified which were seen to stain with von Kossa, suggesting a diagnosis of malakoplakia. Further immmunohistochemistry revealed the cells to express vimentin and CD68 consistent with the diagnosis (fig. 2).

Subsequently, bronchoalveolar lavage was performed and the samples obtained were negative for virology, bacteriology, mycology and Pneumoncistis jiroveci. Samples were specifically tested for organisms known to be isolated in malakoplakia, such as Rhodococcus sp. and Pasteurella sp. The patient was treated with oral ciprofloxacin and reviewed in the clinic. At 3 months her symptoms had resolved and a follow-up CT scan (fig. 3) showed considerable decrease in the size of the lesion.

Malakoplakia is a rare inflammatory condition characterised by the accumulation of macrophages, often giving appearances suggestive of the tumour mass that was first described by Michaelis and GutMAnN [1] in 1902, although first reported in 1901 by Professor von Hansemann [2]. Malakoplakia is essentially a histopathological diagnosis with the characteristic feature being the presences of intra- and extracellular inclusions or calcospherites, termed Michaelis-Gutmann bodies $[1,3,4]$. The pathogenesis has remained a matter of much controversy. The literature suggests that malakoplakia may be related to defective lysosomal activity and microtubular assembly [2]. This leads to impairment of the normal phagocytic process and results in accumulation of benign macrophages, or von Hansemann's cells. The factors leading to
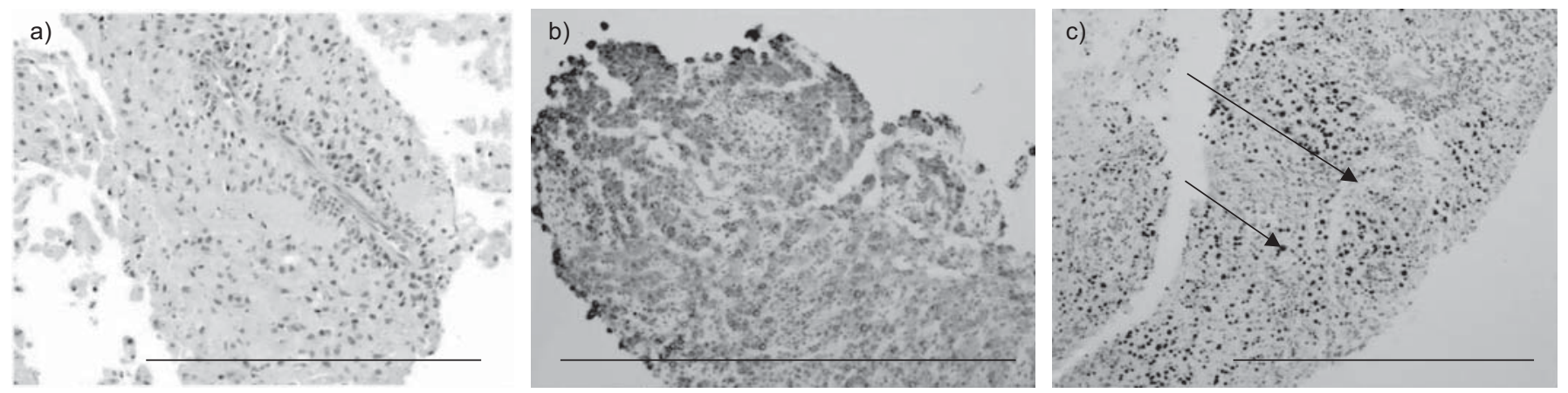

FIGURE 2. a) Imunohistochemistry biopsy revealing fragments of tissue composed of large, bland polygonal cells showing no obvious features of malignancy (haematoxylin and eosin). Scale bar=35.2 mm. b) Immunohistochemistry demonstrating expression of the macrophage marker CD68 as shown by black staining of the cells. Scale bar $=48.0 \mathrm{~mm}$. c) von Kossa stain demonstrating the presence of black inclusion within the cells (arrows) in keeping with Michaelis-Gutmann bodies. Scale bar $=32.0 \mathrm{~mm}$. 
the development of malakoplakia are an unusual strain of bacteria, an altered immune response, an altered histiocytic response or intrinsically abnormal macrophages [5]. The most common site of infection in females is the urinary tract and it is associated with infection with Gram-negative organisms, mainly Escherichia coli and Klebsiella sp. The extragenitourinary sites that are involved are the skin and the pulmonary, renal and gastrointestinal tract. Other microorganisms associated with malakoplakia are Rhodococci equi, Mycobacteria sp., Pasteurella multocida, Proteus mirabilis, Pseudomonas aeruginosa, Yersinia sp., Staphylococcus aurues and fungal infection [6-9]. Thus, in cases such as ours where no positive microbiology is obtained, antibiotics covering Gram-positive and -negative organisms should perhaps be used for at least 2 weeks. So far, less than 40 cases of pulmonary malakoplakia have been reported and there is therefore little evidence for definite treatment.

Pulmonary malakoplakia can present as a lung mass with radiological findings consistent with malignancy or infection. Signs and symptoms are nonspecific and clinical presentation depends on the organ system involved. Conservative treatment with antibiotics results in the regression of the disease in most cases.

In this case, the patient was immunocompetent and no positive microbiology was obtained on bronchoalveolar lavage. Diagnosis was confirmed on core biopsy under CT guidance of the lesion extending from the left lower lobe of the lung, through the left hemidiaphragm to the upper pole of the left kidney. Although the PET scan was positive, a biopsy was performed to establish and confirm diagnosis. In this instance, this was of immense importance as the diagnosis changed from a radiological diagnosis of stage IV lung cancer to a potentially curable inflammatory condition. PET results must be interpreted within the clinical context and, where possible, a tissue diagnosis is desirable to confirm diagnosis. Our patient was empirically treated with antibiotics for 4 weeks and a subsequent CT scan showed a decrease in the size of the lesion.

In 1996, OZKÜRKçÜGIL et al. [10] reported a case of renal malakoplakia with pulmonary involvement. Diagnosis of malakoplakia was confirmed at nephrectomy. Treatment with antibiotics led to regression of the lung lesion. At present, no case of malakoplakia extending from the kidney to the lung with possible involvement of the spleen has been reported.

\section{P. Mandal*, W.A. Wallace ${ }^{\#}$ and K.M. Skwarski*}

*Depts of Respiratory Medicine, and \#Pathology, Royal Infirmary of Edinburgh, Edinburgh, UK.

Correspondence: P. Mandal, Dept of Respiratory Medicine, Royal Infirmary of Edinburgh, 51 Little France Crescent, Edinburgh, UK. E-mail: pallavimandal@gmail.com

\section{Statement of Interest: None declared}

\section{REFERENCES}

1 Michaelis I, Gutmann C. Uber Einschlusse in Blasentumoren. Z Klin Med 1902; 47: 208.

2 Dasgupta P, Womack C, Turner AG, et al. Malacoplakia: von Hansemann's disease. BJU Int 1999; 84: 464-469.

3 Von Hansemann D. Uber Malakoplakie der Harnblase. Virchows Arch A 1903; 173: 302-308.

4 Lou TY, Teplitz C. Malakoplakia: pathogenesis and ultrastructural morphogenesis. Hum Pathol 1974; 5: 191-207.

5 Stanton MJ, Maxted W. Malacoplakia: a study of the literature and current concepts of pathogenesis, diagnosis and treatment. J Urol 1981; 125: 139-146.

6 Pang LC. Pulmonary malakoplakia coexistent with tuberculosis of the hilar lymph node mimicking malignancy. Respiration 2005; 72: 95-100.

7 Miranda D, Vuletin JC, Kaufman SL. Disseminated histiocytosis and intestinal malakoplakia: occurrence due to Mycobacterium intracellulare infection. Arch Pathol Lab Med 1979; 103: 448-450.

8 Bastas A, Markou N, Botsi C, et al. Malakoplakia of the lung caused by Pasteurella multocida in a patient with AIDS. Scand J Infect Dis 2002; 34: 536-538.

9 Jain M, Arora VK, Singh N, et al. Malakoplakia of the appendix. An unusual association with eggs of Taenia species. Arch Pathol Lab Med 2000; 124: 1828-1829.

10 Ozkürkçügil C, Düzcan E, Gültekin Y, et al. A case of renal parenchymal malacoplakia with bilateral pulmonary lesions. Gökalp A. Br J Urol 1996; 77: 159-160.

DOI: 10.1183/09031936.00002911

\section{Interstitial lung disease in a child heterozygous for the $1549 \mathrm{C} \rightarrow$ GAA (121ins2) mutation of surfactant protein B}

\section{To the Editors:}

The SFTPB gene encodes the hydrophobic pulmonary surfactant protein (SP)-B, which is essential for the build-up of the surfactant layer and lowering of surface tension in the airways. SP-B deficiency was the first reported genetic cause of lethal respiratory distress syndrome (RDS) in infants in 1993 [1].

The phenotype of infants with hereditary SP-B deficiency is of a typically full-term neonate with respiratory failure in the first $24-48$ h of life; diagnosis can be delayed, as affected infants may show initially mild symptoms and not require ventilation or further medical support for some time. Chest radiography shows a bilateral, wide ground-glass pattern consistent with a diagnosis of hyaline membrane disease. Typical histological findings are the presence of periodic acidSchiff-positive eosinophilic material in the alveoli, epithelial cell desquamation, enlarged alveolar macrophages with lamellar inclusions and accumulation of SP-A [2]. Since SP-B 